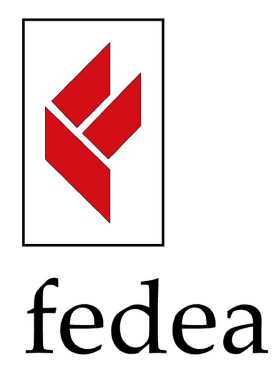

Fundación de

Estudios de

Economía Aplicada

\title{
Trade-offs between environmental regulation and market competition: airlines, emission trading systems and entry deterrence by

\author{
Cristina Barbot ${ }^{*}$, Ofelia Betancor ${ }^{* *}$, \\ M. Pilar Socorro ${ }^{* *}$ and M. Fernanda Viecens ${ }^{* * *}$ \\ Documento de Trabajo 2012-05
}

CÁTEDRA Fedea-Abertis

September 2012

* CEFUP, Faculty of Economics of Porto.

** Universidad de Las Palmas de Gran Canaria and FEDEA.

*** Universidad de San Andrés-CONICET and FEDEA.

Los Documentos de Trabajo se distribuyen gratuitamente a las Universidades e Instituciones de Investigación que lo solicitan. No obstante están disponibles en texto completo a través de Internet: $h t t p: / / w w w . f e d e a . e s$.

These Working Paper are distributed free of charge to University Department and other Research Centres. They are also available through Internet: http://www.fedea.es.

ISSN: $1696-750 \mathrm{X}$ 


\title{
Trade-offs between environmental regulation and market competition: airlines, emission trading systems and entry deterrence $^{\S}$
}

\author{
Cristina Barbot ${ }^{\mathrm{a}, *}$, Ofelia Betancor ${ }^{\mathrm{b}, \mathrm{c}}$, M. Pilar Socorro ${ }^{\mathrm{b}, \mathrm{c}, \#}$ and M. Fernanda Viecens ${ }^{\mathrm{c}, \mathrm{d}}$ \\ ${ }^{a}$ CEFUP, Faculty of Economics of Porto. Rua Roberto Frias, 4200- 464 Porto, Portugal \\ ${ }^{\mathrm{b}}$ Universidad de Las Palmas de Gran Canaria. Departamento de Análisis Económico Aplicado, Campus \\ de Tafira. 35017 Las Palmas de Gran Canaria, Spain
}

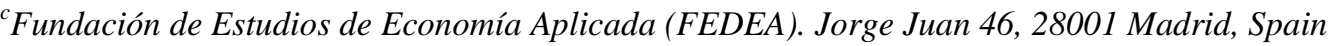

${ }^{d}$ Universidad de San Andrés-CONICET. Vito Dumas 284, 1644, Buenos Aires, Argentina

\begin{abstract}
Emission trading systems (ETS) are being applied worldwide and in different economic sectors as an environmental regulatory tool that induces reductions of $\mathrm{CO}_{2}$ emissions. In Europe such a system is in place since 2005 for energy intensive installations and, since $1^{\text {st }}$ January 2012, for airlines with flights arriving and departing from Community airports. The efficiency of the system should consider not only how it allows reaching an environmental goal, but also it should take into account its implications for market competition. In this work we develop a theoretical model that analyses the European ETS's main features as devised for airlines, focusing on its effects on potential competition and entry deterrence. Contrary to other economic activities under ETS, potential competition is usual in most airline markets. Our results indicate that the share of capped allowances allocated initially for free to air operators may be a key element in deterring or allowing entry into the market. This result may be in collision with the general European principle of promoting competition and may represent a step backwards in the construction of a single European air transport market.
\end{abstract}

Keywords: potential competition, entry deterrence, airlines, emission trading.

\footnotetext{
$\S$ This research was undertaken within the EVA-AIR project, which is funded by the Spanish Ministry of Economics and Competitiveness, research grant ECO 2012-39277. The responsibility for possible errors is solely ours.

* In Memoriam. While we were working in this paper our dear friend and co-author Cristina Barbot sadly passed away. This paper is dedicated to her memory.

\# Corresponding author. Tel.: +34928459605; Fax: +34928458183. E-mail address: psocorro@daea.ulpgc.es.
} 


\section{Introduction}

In Europe the climate change impact of aviation is top on the political agenda. In spite of improvements made to aircraft technology, ${ }^{1}$ the main problem with air transport is its rapid growth that will undermine environmental sustainability in other sectors of the economy (European Commission, 2005). If the current growth continues in the future, the air transport sector will become a major contributor to global warming and climate change.

The aviation sector has special characteristics in this regard. As by definition it is an international activity, it would require an international environmental policy approach. As it was not possible to reach an agreement at Kyoto, it was required that countries would pursue the limitation or reduction of emissions of greenhouse gases working through the ICAO (International Civil Aviation Organization). However, ICAO's recommendation is not to implement an emissions trading system on other Contracting States' aircraft operators except on the basis of mutual agreement between those States. Taking into account this situation, the EU decided to take the lead and include the aviation industry into the European Emission Trading Scheme (EU ETS). Such a system was already in place for other industries in Europe. Directive 2003/87 established the EU ETS affecting energy intensive installations. This piece of legislation was later amended by Directive 2008/101 so as to include aviation activities within the scheme from the $1^{\text {st }}$ of January 2012, and for all flights arriving and departing from Community airports. $^{2}$

According to Directive 2008/101, the basic framework is a rigorous cap on the number of allowances to be allocated. ${ }^{3}$ For the first year of operation of the scheme this cap will be equivalent to 97 percent of the historical aviation emissions, ${ }^{4}$ being lowered to 95 percent for each subsequent period. ${ }^{5}$ The majority of capped allowances will be allocated to air carriers for free, except for the fact that a 15 percent of them would be

\footnotetext{
${ }^{1}$ For instance, fuel burn per passenger seat has been reduced by 70 percent over 40 years (European Commission, 2005). However this result is subject to debate, as pointed out by Peeters et al. (2005).

2 This point has been highly controversial and has resulted in a ruling of the European Court of Justice on December 2011 in a legal case brought by some US airlines.

${ }^{3}$ An allowance or permit is the right to emit one tonne of $\mathrm{CO}_{2}$ during the specified period.

${ }^{4}$ The average mean for years 2004-2006.

${ }^{5}$ Some changes might happen as result of the ongoing review of the whole process.
} 
auctioned and another 3 percent will be reserved for new entrants and for air carriers experiencing a high level of growth. ${ }^{6}$

The amount of allowances or permits to be allocated initially for free will be determined in accordance to airlines' output levels for year 2010. ${ }^{7}$ By the end of April 2012 all air carriers arriving or departing from Community airports should have available enough allowances as to cover emissions produced during year 2011, being possible to buy or sell allowances on the market, or even bank them to cover future emissions. Air carriers unable to surrender enough allowances will be subject to a penalty of 100 euros per tonne of $\mathrm{CO}_{2}$ and will have to surrender the corresponding allowances to cover the incurred emission excess by the next calendar year. In case of non compliance the air carrier can be banned from operations. See Table 1 for a summary of the European ETS as currently applied in Europe to air carriers.

The literature that examines the impacts on airlines markets as derived of such emission trading scheme is relatively recent, starting with CE Delft (2005). In this study increases in airline ticket prices are estimated to be in the range of 0.2 and 9 euros for a round trip, depending on the prices of allowances and routes distances. Forsyth (2008) also reviews the inclusion of aviation activities within ETS schemes as planned for the EU, Australia and New Zealand, analysing their impacts in terms of competition, prices and airlines profitability. The possible impact in terms of the percentage change in fares is estimated to be within a range from 1.6 to 6 percent, depending on the type of route and on whether direct and indirect emissions are included. Nevertheless he notes that the impact on competition and prices will depend on the market structure of specific routes, on whether the short or long run impact is being considered and on whether or not operations are subject to some constraints (e.g. airports capacity constraints).

\footnotetext{
${ }^{6}$ Higher than 18 percent per year.

${ }^{7}$ According to Directive 2008/101 the European Commission will calculate a benchmark to be used as a reference to allocate permits free of charge. This benchmark will be expressed in terms of number of allowances per tonne-kilometre.
} 
Table 1. Summary of the European ETS for aviation activities currently in application

\begin{tabular}{|c|c|}
\hline Main European legislation & Directives 2003/87 and 2008/101 \\
\hline Cap & $97 \%$ of $\mathrm{CO}_{2}$ average emissions during period 2004-2006 \\
\hline $\begin{array}{l}\text { Number of free permits to be } \\
\text { allocated to incumbent airlines } \\
\text { and potential entrants }\end{array}$ & Cap-15\%* of Cap to be auctioned = 85\% of Cap. \\
\hline Benchmark to allocate permits & $\begin{array}{l}\text { It is calculated by the European Commission, and it is given by } \\
\text { the ratio of the number of free permits for incumbents and the } \\
\text { number of total tonne-kilometres produced by all the airlines } \\
\text { under the scheme during the reference period. For the trading } \\
\text { period } 2012 \text { is equivalent to } 0.0006797 \text { allowances per tonne- } \\
\text { kilometres produced during the reference period (European } \\
\text { Commission, 2011). }\end{array}$ \\
\hline Reference period & $\begin{array}{l}\text { 2010. The period used as a reference to obtain free allowances. } \\
\text { The variable utilized for reference is airlines' tonne-kilometres } \\
\text { performed. }\end{array}$ \\
\hline Period to cover emissions & $\begin{array}{l}\text { 2011. Emissions for this year will be monitored and allowances } \\
\text { would have to be surrendered in } 2012 \text { to cover such emissions. }\end{array}$ \\
\hline Trading period & 2012. First year in which allowances would be surrendered. \\
\hline
\end{tabular}

Scheelhaase and Grime (2007) examine the impact on selected European airlines as given from their inclusion in the European ETS under different assumptions. They conclude that implementation of the scheme in its current form would produce relatively moderate financial impacts on airlines, though the impact is likely to be more significant for low cost carriers and regional airlines than for network carriers. They also point out possible competition effects. In this regard, Scheelhaase et al. (2010) 
study the effects on competition between European and non-European network carriers, showing that those based outside the EU and with a moderate growth of emissions between 2006 and 2012, will gain a significant competitive advantage as compared to their European counterparts. On the contrary, Anger (2010) and Anger and Köhler (2010), find negligible impacts of incorporating aviation into the EU ETS. By using a dynamic simulation model they show a negligible reduction in growth rates of the airline industry and its emissions by 2020. However, none of these works analyse how the EU ETS can affect new entrants' decisions and how incumbent airlines may deter entrance. Moreover, we consider this to be a specific feature of airlines markets as opposed to other economic activities in which the issue of potential competition and entry deterrence is not equally applicable. ${ }^{8}$

Environmental regulations may result in an advantage for large firms over small ones and raise concentration (Heyes, 2009). They can discourage entry in their own right and provide instruments with which incumbents can discourage entry strategically (Schoonbeek and Vries, 2009). In this work we will develop a theoretical model that takes into account the European ETS's main features as devised for airlines markets, focusing on its effects on potential competition and entry deterrence.

Entry deterrence consists of altering the initial conditions of the post-entry game to the advantage of the established firm (Dixit, 1980). As it has been designed airlines must decide their production levels in 2010 taking into account that the EU ETS starts in 2012 and that their output decisions in 2010 will affect the amount of free allowances that they will be able to get. Moreover, such scheme introduces a special reserve of free allowances for new entrants and for incumbent airlines with a high level of growth; hence the special reserve may be shared among both groups: new entrants and incumbent airlines. We will show that such a setting may result in entry deterrence affecting competition levels and social welfare. This result collides with the general European principle of promoting competition and may represent a step backwards in the construction of a single European air transport market.

\footnotetext{
${ }^{8}$ Apart from air transport, the other activities subject to the European ETS, are listed in Annex I of Directive 2003/87, and are the following: energy activities, production and processing of ferrous metals, mineral industry and industrial plants for the production of pulp from timber, paper and board.
} 
After this introduction, section 2 is dedicated to present the main features of the theoretical model. Section 3 shows the modelling results and the market equilibrium, given the ETS regulation. Section 4 analyses how the environmental regulator may induce each type of equilibrium when establishing the ETS. Finally, the conclusions and policy implications derived from the modelling results are presented in section 5.

\section{The Model}

We consider a market which is operated just by one airline, airline $I$ (the incumbent). However, there is a potential entrant, airline $E$, that may enter the market. The demand function of this market is given by:

$$
P=a-Q,
$$

where $P$ denotes the ticket price, $Q$ represents the total amount of tonne-kilometres flown in this market, and $a$ represents the market size. Marginal operating costs are assumed to be constant and identical for both the incumbent and the potential entrant and, for the sake of simplicity, they are set to zero. ${ }^{9}$ We assume that, if the potential entrant decides to operate in the market, he faces a fixed entry cost denoted by $F$.

In this context the regulator decides to introduce an ETS in the market and give airlines some permits for "free". If airlines need more permits they should buy them. On the contrary, if they need fewer permits they will be able to sell them in the market. Let $Z$ be the competitive price for permits ${ }^{10}$ and let $\bar{A}$ be the "free" permits available for the air transport sector, with $\bar{A}=\delta a .{ }^{11}$ Permits are distributed to the incumbent airline in proportion $\alpha \in(0,1)$ to tonne-kilometres flown during a reference period while the rest of permits are reserved for new entrants. ${ }^{12}$

\footnotetext{
${ }^{9}$ The literature on costs functions for transportation is quite extensive. In particular, Oum and Waters (1997), find many examples of constant returns to scale for the air transport industry in the case of airlines (seven out of ten studies).

${ }^{10}$ We do not consider that permits may be auctioned since in equilibrium the auction price should tend to the competitive price of permits.

${ }^{11}$ As in Directive 2008/101, we assume that the cap is a percentage of the historical aviation emissions, that is, a percentage of the market size.

${ }^{12}$ Note that $\alpha$ is a benchmark calculated by the European Commission. See also footnote 7 above and Table 1.
} 
Let $Q_{I, t}$ be the quantity flown by the incumbent during the reference period $t$. Then, the incumbent receives $\alpha Q_{I, t}$ permits and the rest of permits are reserved to the potential entrant, that is, $\bar{A}-\alpha Q_{I, t}$.

Once the ETS starts, we assume that the production can be done either through permits or by reducing the level of emissions. Denote by $A_{j}$ the amount of permits used by airline $j$, where $j=I, E$, and by $\lambda_{j}$ the efficiency of airline $j$ in reducing its emissions through an abatement effort $e_{j}$. As usual in the literature, the cost of abatement effort is assumed to be quadratic, that is, $c\left(e_{j}\right)=\frac{e_{j}^{2}}{2}$, for every $j .{ }^{13}$ We assume that each unit of abatement effort reduces the emissions in $\lambda_{j}$ units and thus, airline $j$ can fly this extra amount of tonnes-kilometre. Formally, $Q_{j}=A_{j}+\lambda_{j} e_{j}$.

In order to guarantee that the model is well defined and to rule out corner solutions we develop our model under three assumptions. First, we assume that $\delta>\alpha$, that is, even if the incumbent flies the maximum quantity $a$ during the reference period, there are some permits reserved for the potential entrant, $(\delta-\alpha) a$. Second, $\lambda_{I} \neq 0$ and $\lambda_{E} \neq 0$, meaning that the abatement effort effectively reduces emissions for both airlines. Third, $a>\max \left(3 Z \lambda_{E}^{2}+Z, 3 Z \lambda_{I}^{2}+Z\right)$. This latter condition imposes that the market size $a$ must be large enough when compared to the competitive price of permits $Z$ and exceeds $Z$ in a factor that depends on the effectiveness of the abatement effort of the most environmentally efficient airline.

The timing of the game is as follows:

- Period 1 ( $t=1):{ }^{14}$ the regulator decides the value of $\alpha \in(0,1)$. Then, he announces that a new ETS will be set for the market in period 3, where some free permits will be distributed to the incumbent in proportion $\alpha$ to tonne-

\footnotetext{
13 The assumption of quadratic costs for abatement effort is usually applied in the environmental economics literature. Some examples are Calthrop and Proost (2003), Chavez and Stanlund (2003), Hoel and Karp (2001), Nannerup (1998), or Yates and Cronshaw (2001).

${ }^{14}$ In Europe this corresponds to year 2008 in which Directive 2008/101 is published.
} 
kilometres flown during period 2. The rest of permits are reserved to potential entrants.

- Period $2(t=2):{ }^{15}$ the incumbent of the route decides how much to produce taking into account that in the next period the ETS takes place and that the amount of permits it will receive is proportional to the quantity flown during this period 2.

- Period $3(t=3):{ }^{16}$ the ETS takes place and a potential entrant decides whether or not to enter the market. If the potential entrant enters he pays the fixed entry cost and airlines compete à la Cournot. If the potential entrant does not enter, the incumbent operates as a monopoly.

The game is solved by backward induction. See Table 2 for a summary of notation.

Note that our model approaches Dixit (1980)'s analysis in which an incumbent decides whether to accommodate entry or to deter it by overinvesting. However, there are also substantial differences. In Dixit (1980), the established firm chooses a pre-entry capital level. This capital level may subsequently be increased, but cannot be reduced and, thus, implies a sunk cost for the incumbent. This irrevocable commitment of investment may alter the initial conditions of the post-entry game to the advantage of the established firm, producing entry-deterrence. However, in our model, instead of investing in capacity, the incumbent may deter entry in period 3 by obtaining a greater number of free allowances, which in turn will be dependent on its production level in period 2 . Contrary to Dixit (1980), this decision does not imply a sunk cost for the incumbent, since extra free allowances can be sell in the market or even bank for covering future emissions. We also develop a model with a regulator who plays a crucial role, in contrast to Dixit (1980)'s where there is no regulation.

\footnotetext{
${ }^{15}$ This period is known as the "reference period" and currently corresponds to year 2010. Note also that during this reference period the entrant has not entered the market yet.

${ }^{16}$ This period currently corresponds to year 2011 and consequently airlines should have available enough allowances to cover $\mathrm{CO}_{2}$ emissions produced during this year. The surrender of allowances takes place in the following year also known as the "trading period". For simplicity we have not included a period 4 in our analysis.
} 
Table 2. Summary of notation

\begin{tabular}{|l|l|}
\hline$I$ & Incumbent \\
\hline$E$ & Potential entrant \\
\hline$P$ & Airlines' ticket price \\
\hline$Q$ & Airlines' output level (tonne-kilometres) \\
\hline$a$ & Demand parameter for market size \\
\hline$F$ & Fixed entry cost for the potential entrant \\
\hline$Z$ & Competitive price of permits \\
\hline $\bar{A}$ & Total number of free permits for the incumbent and the potential entrant \\
\hline$\delta$ & Percentage on the market size to define cap based on historical emissions \\
\hline$\lambda_{i}$ & Parameter denoting the efficiency of airline $i$ in reducing emissions through abatement effort \\
\hline
\end{tabular}

\section{Market equilibrium}

In this section we analyse backwards all possible market outcomes once the ETS has been established. First, we find the two potential period 3 solutions, when the market is a monopoly, and when entry has occurred. Second, we find the quantity that the incumbent needs to fly in period 2 in order to block, deter or accommodate the entry. Finally, we analyze the necessary conditions for blocked, deterred and accommodated entry.

\section{1. Period 3: monopoly and duopoly solutions}

In period 3 all airlines operating in the air transport sector are included in the ETS. The incumbent receives $\alpha Q_{I, 2}$ permits for free. If the potential entrant enters, he receives $\bar{A}-\alpha Q_{I, 2}$ permits for free. Recall that $A_{j}$ denotes the amount of permits used by airline 
$j$. Thus, if the expression $\left(\alpha Q_{I, 2}-A_{I}\right)$ is positive (negative), it represents the extra permits sold (bought) by the incumbent in the ETS market. On the contrary, if the expression $\left(\bar{A}-\alpha Q_{I, 2}-A_{E}\right)$ is positive (negative), it represents the extra permits sold (bought) by the entrant in the ETS market.

The monopoly solution

Let us denote by $\Pi_{I, 3}^{M}$ the profits obtained by the incumbent as a monopolist in period 3. As a monopolist, the incumbent solves the following maximization program:

$$
\begin{aligned}
\underset{A_{I}, e_{I}}{\operatorname{Max}} \Pi_{I, 3}^{M}=\left(a-Q_{I, 3}\right) Q_{I, 3}+Z\left(\alpha Q_{I, 2}-A_{I}\right)-\frac{\left(e_{I}\right)^{2}}{2} \\
\text { s.t. } \quad Q_{I, 3}=A_{I}+\lambda_{I} e_{I} .
\end{aligned}
$$

First order conditions yield as optimal solution: $e_{I}^{M}=Z \lambda_{I}$ and $A_{I}^{M}=\frac{1}{2}(a-Z)-Z \lambda_{I}^{2}$. Note that our assumption on the market size, that is, $a>\max \left(3 Z \lambda_{E}^{2}+Z, 3 Z \lambda_{I}^{2}+Z\right)$, ensures an interior solution, that is, $A_{I}^{M}>0$. This solution generates the following profits to the incumbent:

$$
\Pi_{I, 3}^{M}=\frac{1}{4}\left((a-Z)^{2}+2 Z^{2} \lambda_{I}^{2}+4 Z \alpha Q_{I, 2}\right) .
$$

The duopoly solution

Denote by $\Pi_{I, 3}^{C}$ the incumbent's profits and by $\Pi_{E, 3}^{C}$ the entrant's profits in a duopoly market in period 3. Since the two airlines compete à la Cournot, the incumbent solves the following maximization program:

$$
\begin{gathered}
\underset{A_{I}, e_{I}}{\operatorname{Max}} \Pi_{I, 3}^{C}=\left(a-Q_{I, 3}-Q_{E, 3}\right) Q_{I, 3}+Z\left(\alpha Q_{I, 2}-A_{I}\right)-\frac{e_{I}^{2}}{2} \\
\text { s.t. } \quad Q_{I, 3}=A_{I}+\lambda_{I} e_{I},
\end{gathered}
$$

where $Q_{I, 3}$ stands for the incumbent's quantity in period 3 and $Q_{E, 3}$ for the entrant's quantity in the same period. 
Profit maximization by the incumbent yields the following best reply functions (BRFs):

$$
\begin{aligned}
& a-Z-Q_{E, 3}-2 A_{I}-2 \lambda_{I} e_{I}=0 . \\
& a \lambda_{I}-e_{I}-\lambda_{I} Q_{E, 3}-2 \lambda_{I} A_{I}-2 \lambda_{I}^{2} e_{I}=0 .
\end{aligned}
$$

On the other hand, the entrant solves the following maximization program:

$$
\begin{aligned}
\underset{A_{E}, e_{E}}{\operatorname{Max}} \Pi_{E, 3}^{C}= & \left(a-Q_{I, 3}-Q_{E, 3}\right) Q_{E, 3}+Z\left(\bar{A}-\alpha Q_{I, 2}-A_{E}\right)-\frac{e_{E}^{2}}{2}-F \\
\text { s.t. } & Q_{E, 3}=A_{E}+\lambda_{E} e_{E} .
\end{aligned}
$$

BRFs for the entrant are given by:

$$
\begin{aligned}
& a-Z-2 A_{E}-A_{I}-2 \lambda_{E} e_{E}-\lambda_{I} e_{I}=0 . \\
& a \lambda_{E}-e_{E}-2 \lambda_{E} A_{E}-\lambda_{E} A_{I}-2 \lambda_{E}^{2} e_{E}-\lambda_{E} \lambda_{I} e_{I}=0 .
\end{aligned}
$$

By simultaneously solving the BRFs given by expressions (2) and (3), we obtain the duopoly solutions for period 3:

$$
\begin{aligned}
& A_{I}=\frac{1}{3}(a-Z)-Z \lambda_{I}^{2} ; e_{I}=Z \lambda_{I} . \\
& A_{E}=\frac{1}{3}(a-Z)-Z \lambda_{E}^{2} ; e_{E}=Z \lambda_{E} .
\end{aligned}
$$

Our assumptions on $\lambda_{I}, \lambda_{E}$ and $a$ ensure that $A_{I}, A_{E}, e_{I}$ and $e_{E}$ are positive, that is, both airlines use permits and exert an abatement effort that is proportional to the competitive price of permits and the efficiency of each airline. As expected, $A_{I}$ and $A_{E}$ negatively depend on the permit's price $Z$, and on each airline's abatement effort.

Inserting the optimal solutions into the airlines' profit functions, we obtain period 3's profits, which are given by:

$$
\begin{gathered}
\Pi_{I, 3}^{C}=\frac{1}{2} Z^{2} \lambda_{I}^{2}+\frac{1}{9}(a-Z)^{2}+\alpha Z Q_{I, 2} . \\
\Pi_{E, 3}^{C}=\frac{1}{2} Z^{2} \lambda_{E}^{2}+\frac{1}{9}(a-Z)^{2}+Z a \delta-\alpha Z Q_{I, 2}-F .
\end{gathered}
$$


Notice that the incumbent's profits positively depend on $\alpha$ and on $Q_{I, 2}$. The higher the share of permits the regulator allocates for this airline and the larger the number of permits it obtains for free in period 3 (which also depends on $Q_{I, 2}$ ), the more it can produce without buying permits and so the lower its costs. The opposite happens for the entrant's profits, which decrease with $\alpha$ and with $Q_{I, 2}$. Then, the lower the costs for each airline the more it produces and the higher its profits are. On the contrary, lower costs for an air carrier also means that its rival will produce less obtaining lower profits. This is a standard result of the Cournot model. In particular, this trade-off on quantities and profits between the two airlines will allow the incumbent, who has a first mover advantage when choosing its quantity for period 2 , to decide on whether it allows the entrant to enter and compete in the market, or if it rather prefers to deter the entry.

Finally, notice that the entrant's profits negatively depend on the fixed entry cost $F$ and, thus, independently on the amount of permits he will obtain for free he may decide not to enter.

\section{2. Period 2: the incumbent's choice of quantity during the reference period}

As discussed in the previous section, $\frac{\partial \Pi_{E, 3}^{C}}{\partial \alpha}<0$ holds. Also, for a given $\alpha$, the entrant's profits negatively depend on $Q_{I, 2}, \frac{\partial \Pi_{E, 3}^{C}}{\partial Q_{I, 2}}=-\alpha Z<0$, and $F, \frac{\partial \Pi_{E, 3}^{C}}{\partial F}<0$. As a result of the regulator choice of $\alpha$ in period 1 and the level of the fixed entry cost, two situations may occur:

1) For any value of $\alpha$ set by the regulator, the fixed entry cost is so high that $\Pi_{E, 3}^{C} \leq 0$ occurs independently of the incumbent's choice for its quantity in period 2. Alternatively, the fixed entry cost is not excessive but the value $\alpha$ set by the regulator is so high that $\Pi_{E, 3}^{C} \leq 0$, independently of the incumbent's quantity in period 2. Whenever any of these situations happens, we will say that entry is blocked.

2) The level of the fixed entry cost and the value of $\alpha$ chosen by the regulator allows for equilibria under which the entrant may obtain positive profits if entry 
happens. In this case the incumbent may induce a deterred or an accommodated entry.

\section{Blocked entry}

If entry is blocked, in period 2 the incumbent anticipates that the entrant will never enter and chooses a quantity for period 2 that maximizes the sum of the profits it obtains, as a monopoly, in periods 2 and 3 :

$$
\Pi_{I}^{M}=\Pi_{I, 2}^{M}+\Pi_{I, 3}^{M}=\left(a-Q_{I, 2}\right) Q_{I, 2}+\frac{1}{4}\left(2 Z^{2} \lambda_{I}^{2}+(a-Z)^{2}+4 Z \alpha Q_{I, 2}\right)
$$

which yields: $Q_{I, 2}=\frac{1}{2}(a+\alpha Z)$.

Substituting $Q_{I, 2}$ by the above optimal solutions in the incumbent's monopoly profits we obtain the following:

$$
\Pi_{I}^{M}=\Pi_{I, 2}^{M}+\Pi_{I, 3}^{M}=\frac{1}{4}\left(Z^{2} \alpha^{2}+2 Z^{2} \lambda_{I}^{2}+(a-Z)^{2}+2 Z a \alpha\right)
$$

Therefore, if given $Q_{I, 2}=\frac{1}{2}(a+\alpha Z)$ the level of $F$ or the value of $\alpha$ set by the regulator is such that $\Pi_{E, 3}^{C} \leq 0$, then, entry is blocked.

A different situation occurs if the level of $F$ is not excessive and the regulator sets a value of $\alpha$ that allows for positive profits for the entrant. In this case, after observing the value of $\alpha$ set in period 1 , the incumbent may:

1) Set $Q_{I, 2}$ that allows entry and compete à la Cournot with the entrant: it is an accommodated entry.

2) Choose a quantity $Q_{I, 2}$ that leads to $\Pi_{E, 3}^{C} \leq 0$ : it is a deterred entry.

The incumbent will choose the option that yields higher profits. For this purpose, we will next compute the incumbent's profits for the two periods in the case of accommodated entry and of entry deterrence. 


\section{Accommodated entry}

If entry is accommodated, the duopoly solution prevails for period 3. In period 2 the incumbent, acting as a monopoly, will choose $Q_{I, 2}$ in order to maximize both periods' profits, which are:

$$
\Pi_{I, 2}^{M}+\Pi_{I, 3}^{C}=\left(a-Q_{I, 2}\right) Q_{I, 2}+\frac{1}{2} Z^{2} \lambda_{I}^{2}+\frac{1}{9}(a-Z)^{2}+\alpha Z Q_{I, 2},
$$

yielding $Q_{I, 2}=\frac{1}{2}(a+\alpha Z)$, which is identical to the value of $Q_{I, 2}$ for the monopoly situation.

Inserting the solution for $Q_{I, 2}$ in the profit functions we have that the incumbent's profits in periods 2 and 3 if the entry is accommodated are given by:

$$
\Pi_{I, 2}^{M}+\Pi_{I, 3}^{C}=\frac{1}{4} Z^{2} \alpha^{2}+\frac{1}{2} Z^{2} \lambda_{I}^{2}+\frac{1}{9} Z^{2}+\frac{1}{2} Z^{2} a \alpha-\frac{2}{9} Z a+\frac{13}{36} a^{2} .
$$

\section{Deterred entry}

If entry is deterred then the incumbent will choose a value of $Q_{I, 2}$ that leads to zero profits for the entrant:

$$
\Pi_{E, 3}^{C}=\frac{1}{2} Z^{2} \lambda_{E}^{2}+\frac{1}{9}(a-Z)^{2}+Z a \delta-\alpha Z Q_{I, 2}-F=0
$$

that is, $Q_{I, 2}^{E D}=\left(9 Z^{2} \lambda_{E}^{2}+18 Z a \delta+2(a-Z)^{2}-18 F\right) / 18 \alpha Z$, where $Q_{I, 2}^{E D}$ denotes the entry deterrence quantity of the incumbent in period 2. Such a quantity must be positive and lower or equal than the market size $a$.

Lemma 1: Entry deterrence is possible if and only if $F_{0} \leq F \leq F_{1}$, with $F_{0}=\frac{1}{2} Z^{2} \lambda_{E}^{2}+\frac{1}{9}(a-Z)^{2}+Z a(\delta-\alpha)$ and $F_{1}=\frac{1}{2} Z^{2} \lambda_{E}^{2}+\frac{1}{9}(a-Z)^{2}+Z a \delta$.

Proof: See the Appendix. 
If $F_{o} \leq F \leq F_{1}$, by setting $Q_{I, 2}^{E D}$ in period 2 the incumbent will be a monopoly in both periods, producing $Q_{I, 2}^{E D}$ in period 2. By substituting $Q_{I, 2}$ by $Q_{I, 2}^{E D}$ in the monopoly profits, we obtain the expression of the incumbent's entry deterrence profits for both periods 2 and 3 :

$$
\begin{aligned}
& \Pi_{I, 2}^{E D}+\Pi_{I, 3}^{E D}=\frac{1}{2} Z^{2}\left(\lambda_{E}^{2}+\lambda_{I}^{2}\right)+\frac{13}{36}(a-Z)^{2}+Z a \delta-F- \\
& \frac{\left(9 Z^{2} \lambda_{E}^{2}-18 F+2(a-Z)^{2}+18 Z a \delta\right)\left(9 Z^{2} \lambda_{E}^{2}-18 F+2(a-Z)^{2}+18 Z a(\delta-\alpha)\right)}{324 Z^{2} \alpha^{2}} .
\end{aligned}
$$

\subsection{Conditions for blocked, deterred and accommodated entry}

Let us now analyze the values of $F$ and $\alpha$ for which entry is blocked, deterred or accommodated. Entry is blocked if, even if the incumbent decides to exert its monopoly

position in both periods (by setting $Q_{I, 2}=\frac{1}{2}(a+\alpha Z)$ ), the duopoly profits for the entrant $\Pi_{E, 3}^{C}$ are lower than zero. This will be the case if $F$ or $\alpha$ are sufficiently large, as shown in the following lemmas.

Lemma 2: If $F>F_{1}$, entry is blocked.

Proof: See the Appendix.

Lemma 2 implies that, independently of the value of $\alpha$, entry may be blocked if $\mathrm{F}$ is sufficiently high. In contrast, the following lemma shows that when $F$ is not too large, entry may be blocked if $\alpha$ is large enough.

Lemma 3: For any $F \leq F_{1}$, there exists $\alpha^{*} \geq 0$ such that,

i) if $\alpha>\alpha^{*}$ entry is blocked,

ii) $\alpha^{*}$ is a decreasing and concave function of $F$.

iii) $\alpha^{*}$ is zero for $F=F_{1}$, i.e. $\alpha^{*}\left(F_{1}\right)=0$.

Proof: See the Appendix. 
From Lemma 1 we know that entry deterrence is possible if and only if $F_{0} \leq F \leq F_{1}$. Furthermore., for any $F<F_{0}$ and $\alpha \leq \alpha^{*}$ entry cannot be blocked or deterred and, thus, the incumbent accommodates the entry.

Lemma 4: For any $F<F_{0}$ and $\alpha \leq \alpha^{*}$ entry is accommodated.

Figure 1 summarizes all the results contained in lemmas 2, 3 and 4. Notice that, as stated in Lemma 1, the critical value $F_{1}$ is independent of the value of $\alpha$. However, the critical value $F_{0}$ is a linear and strictly decreasing function of $\alpha$. Lemma 2 shows that, independently of the value of $\alpha$, if $F>F_{1}$ entry is blocked. Lemma 3 shows that for any $F \leq F_{1}$ and $\alpha>\alpha^{*}$ entry is blocked. Lemma 4 states that for any $F<F_{0}$ and $\alpha \leq \alpha^{*}$ entry is accommodated. However, if $F_{0} \leq F \leq F_{1}$ entry deterrence is possible so the condition $\alpha \leq \alpha^{*}$ just guarantees that entry cannot be blocked but, it can be deterred or accommodated.

Figure 1: Conditions for blocked entry and conditions for accommodated entry if $F<F_{0}$

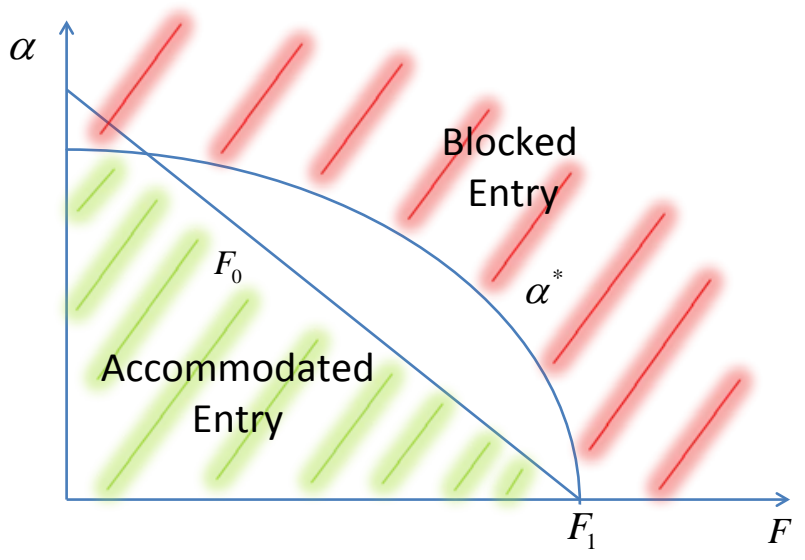

Given $F_{0} \leq F \leq F_{1}$, entry is deterred if the profits that the incumbent obtains when he produces in the second period a quantity sufficiently high to induce negative duopoly profits for the entrant, $\Pi_{I, 2}^{E D}+\Pi_{I, 3}^{E D}$, are higher than the profits he obtains when entry is accommodated. That is, when he just chooses in the second period the quantity that maximizes his profits, knowing that in the third period he will compete à la Cournot with the entrant, and will obtain $\Pi_{I, 2}^{M}+\Pi_{I, 3}^{C}$. 
Lemma 5: If $F_{0} \leq F \leq F_{1}$, there exists $\bar{\alpha} \in\left(0, \alpha^{*}\right)$ such that,

i) if $\alpha<\bar{\alpha}$ entry is accommodated,

ii) if $\alpha>\bar{\alpha}$ entry is deterred.

Proof: See the Appendix.

Figure 2 plots the profits for the incumbent in periods 2 and 3, both if entry is deterred and if entry is accommodated, and $F_{0} \leq F \leq F_{1}$. If $\alpha<\bar{\alpha}, \quad \Pi_{I, 2}^{E D}+\Pi_{I, 3}^{E D}<\Pi_{I, 2}^{M}+\Pi_{I, 3}^{C}$, and thus, the incumbent just accommodates the entry. If $\alpha>\bar{\alpha}, \quad \Pi_{I, 2}^{E D}+\Pi_{I, 3}^{E D}>\Pi_{I, 2}^{M}+\Pi_{I, 3}^{C}$, and the incumbent will decide to deter the entry.

Figure 2: Conditions for deterred and accommodated entry if $F_{0} \leq F \leq F_{1}$

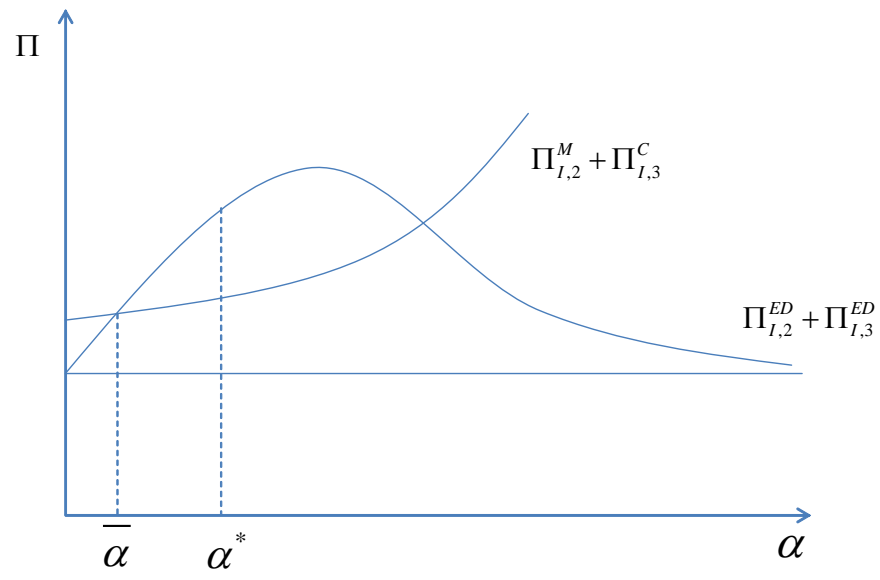

From Lemmas 2, 3 and 4 we can conclude that if $F$ is high enough entry is blocked. If $F$ is low enough entry deterrence is not possible and, thus, in this case if $\alpha$ is lower than $\alpha^{*}$ entry is just accommodated. For intermediate values of $F$ entry may be blocked, deterred or accommodated depending on the value of $\alpha$. Consequently, we can conclude that the choice of $\alpha$ may have important consequences on the level of competition of the industry. In next section we will analyze the circumstances under which the regulator should be careful in the selection of $\alpha$ if he wants to promote competition in the market. 


\section{The ETS regulation and its effect on the equilibrium market}

In the first period the regulator announces that a new ETS will be set for the market in the third period, where permits will be given to the incumbent in proportion $\alpha$ to the tonne-kilometres flown during the second period. The rest of permits are reserved to potential entrants. Before announcing the ETS the regulator must decide the value of $\alpha \in(0,1)$. As we will show, the regulator's decision on the value of $\alpha$ may have important consequences on the level of competition to be faced during the third period.

Proposition 1: For any $F \leq F_{1}$ :

i) The blocked entry equilibrium is induced by the regulator as long as $\alpha>\alpha^{*}$ is set.

ii) An accommodated entry equilibrium is induced by the regulator as he sets $\alpha<\alpha^{*}$ when $F<F_{0}$, or $\alpha<\bar{\alpha}$ when $F_{0} \leq F \leq F_{1}$.

iii) An entry deterrence equilibrium is induced by the regulator as he sets $\alpha^{*}>\alpha>\bar{\alpha}$, whenever $F_{0} \leq F \leq F_{1}$.

To illustrate the main results of this paper that are summarized in Proposition 1 we now present a numerical example. Consider the following values for the parameters $a=110, \lambda_{I}=1, \lambda_{E}=2, Z=1, \delta=0.97$. For these values, $\alpha^{*}=\frac{1}{6} \sqrt{1.7554 \times 10^{5}-72 F}-50$ and $F_{0}=1188-100 \alpha$. We can rewrite the latter expression as $\alpha_{o}=11.88-0.01 F$.

Figure 3 plots the critical values of $\alpha^{*}$ and $\alpha_{0}$ as functions of the fixed entry cost $F$.

Take $F=1180$ then, $\bar{\alpha}=0.1045$ and $\alpha^{*}=0.1597$. Consequently, if the regulator sets $\alpha$, such that, $\alpha \in(0.1045,0.1597)$ there is an entry deterrence equilibrium. If the regulator sets $\alpha>0.1597$, entry is blocked. Finally, if $\alpha<0.1045$ is chosen, entry is accommodated in equilibrium. 


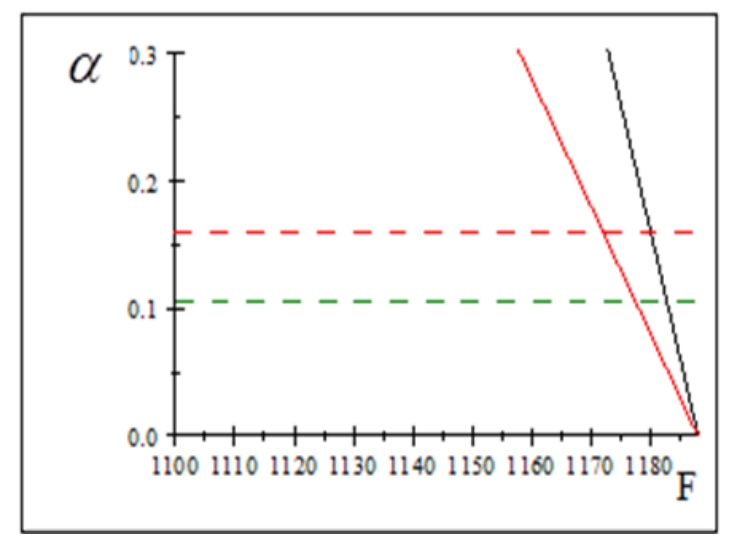

For any $F<F_{1}$ lemmas 3 and 4 guarantee that thresholds $\alpha^{*}$ and $\bar{\alpha}$ are higher than zero. However, they do not guarantee that such thresholds are lower or equal than one.

Lemma 6: The threshold $\alpha^{*}$ is higher than one, $\alpha^{*}>1$, if (i) $a>a^{*}=\frac{13}{4} Z-\frac{9}{2} Z \delta+\frac{3}{4} \sqrt{36 Z^{2} \delta^{2}-52 Z^{2} \delta-8 Z^{2} \lambda_{E}^{2}+25 Z^{2}+16 F}, \quad$ or $36 Z^{2} \delta^{2}-52 Z^{2} \delta-8 Z^{2} \lambda_{E}^{2}+25 Z^{2}+16 F<0$. The threshold $\bar{\alpha}$ is higher than one, $\bar{\alpha}>1$, if $\alpha^{*}>1$ and $\Pi_{I, 2}^{E D}+\Pi_{I, 3}^{E D}<\Pi_{I, 2}^{M}+\Pi_{I, 3}^{C}$ for $\alpha=1$.

\section{Proof: See the Appendix.}

The threshold $\alpha^{*}$ is higher than one if the market size is higher than a critical value $a^{*}$ or if such a critical value does not exist. The latter condition is more likely to be fulfilled the higher $\lambda_{E}$ is (that is, the more efficient is the entrant in reducing his emissions through abatement effort) and the lower the fixed entry cost $F$ is. Thus, the higher $a$ or $\lambda_{E}$ are, or the lower $F$ is, the more likely is that entry cannot be blocked. The threshold $\bar{\alpha}$ is higher than one if the threshold $\alpha^{*}$ is higher than one and the profits obtained by the incumbent if the entry is accommodated are higher than the profits he would obtain if the entry is deterred for any $\alpha \in(0,1)$ set by the regulator. In this latter case, entry will be never deterred.

We have shown that thresholds $\alpha^{*}$ and $\bar{\alpha}$ may be higher than one. However, the value of $\alpha$ to be chosen by the regulator must be within the open interval $(0,1)$. Thus, the 
selection of $\alpha$ made by the regulator may have no effect on the level of competition, as we show in the following corollary.

Corollary 1: If $F>F_{1}$ entry is always blocked and the selection of $\alpha$ has no effect on the level of competition. If $F<F_{0}$ and $\alpha^{*}>1$ entry is always accommodated and the selection of $\alpha$ has no effect on the level of competition. If $F_{0} \leq F \leq F_{1}$ and $\bar{\alpha}>1$ entry is always accommodated and the selection of $\alpha$ has no effect on the level of competition.

\section{Conclusions}

From year 2012 airlines operating in Europe will be subject to the European ETS. This is a system in application within Europe since year 2003 also for other economic activities, most of them energy intensive installations. We believe that airlines markets are substantially different than those activities, especially in what regards competition issues. Airlines markets can be highly competitive in some routes, being a classical instance of contestable markets. On the contrary, energy intensive installations usually show natural monopoly features at least in an important part of their activities. In such industries, fixed entry costs are so high that entry is usually blocked, independently of the specific characteristics of the ETS. This is not usually the case of air transport markets and, thus, the analysis of the implications for competition as derived from their inclusion within the European ETS, and in particular for potential competition and entry deterrence, appears as of special importance in the case of air markets.

Similarly to the Dixit (1980)'s model, the incumbent airline has available a strategic variable to deter entry if this is required. We have identified that such strategic variable is given by its choice of output during the period utilized as reference in order to obtain free pollution permits. In this case the incumbent airline does not need to make a higher investment in capacity, but to produce as much output as possible in order to get a higher number of free allowances and hence deter entry.

We have developed a theoretical model that also aims to highlight under what conditions the entry is blocked, deterred or accommodated. Although the level of output for the incumbent in the reference period is a critical variable in our model, it is not the only important variable to be considered. The level of the fixed cost and the choice of 
the benchmark made by the European Commission for the free allocation of permits are also of special importance.

We have shown that the incumbent may be facing different combinations of fixed entry costs for the potential entrant and ETS benchmarks that make him to select an output level that may be either consistent with a situation of blocked, deterred or accommodated entry. Therefore his choice will be dependent on both variables. With respect to the former, and taking into account the general competitive level within European air transport markets, ${ }^{17}$ we tend to think that these entry costs are in general not sufficiently high to block entry in absence of any ETS. However, the introduction of the ETS and the choice of the benchmark, which is calculated by the Commission in accordance to airlines requests, can be sufficiently high to induce a situation in which the entry is completely blocked.

The implications for potential competition and entry deterrence pointed out in this work were probably overlooked by the European Commission when devising the inclusion of aviation within the European ETS. Just the possibility of allocating permits for free is troublesome, not only because airlines are not paying for their full social costs, but also for the fact that there may be important distortions to competition in a highly competitive environment. In this sense a movement towards a whole system based on auctioning of allowances would be advisable, as indeed is already happening with energy intensive installations activities.

\section{References}

Anger, A. (2010). 'Including aviation in the European emissions trading scheme: impacts on the industry, $\mathrm{CO}_{2}$ emissions and macroeconomic activity in the EU'. Journal of Air Transport Management. Vol. 16, Issue 2, pp. 100-105.

Anger, A., and J. Köhler, (2010). 'Including aviation emissions in the EU-ETS: Much ado about nothing? A review’. Transport Policy. Vol.17, Issue 1, pp. 38-46.

\footnotetext{
${ }^{17}$ The number of intra-European routes with more than two competitors tripled in the period 1992-2009 (European Commission, 2009).
} 
Calthrop, E. and S. Proost (2003): "Environmental Pricing in Transport", in Hensher, D. A. and K. J. Button (eds.), Handbook of Transport and the Environment, Elsevier Science Ltd, chapter 29, 529-545.

CE Delf, (2005). 'Giving wings to emission trading: inclusion of aviation under the emission trading system’. Report for the European Commission. DG Environment.

Chavez, C. A. and J. K. Stanlund (2003): "Enforcing transferable permit systems in the presence of market power", Environmental and Resource Economics 25(1), 65-78.

Dixit, A. (1980). 'The role of investment in entry deterrence'. The Economic Journal. Vol. 90, No. 357, pp. 95-106.

European Commission, (2005). Communication from the Commission to the Council, the European Parliament, the European Economic and Social Committee and the Committee of the Regions. Air Transport and the Environment. Reducing the climate change impact of aviation. COM (2005), 459 final.

European Commission (2009). Facts and key developments on air transport. Available at: http://ec.europa.eu/transport/air/doc/03_2009_facts_figures.pdf

European Commission, (2011) Decision on benchmarks to allocate greenhouse gas emission allowances free of charge to aircraft operators pursuant to Article $3 \mathrm{e}$ of Directive 2003/87/EC of the European Parliament and of the Council.

Forsyth, P., (2008). 'The impact of climate change policy on competition in the air transport industry'. Discussion Paper No. 2008-18 prepared for the Round Table on Airline Competition, Systems of Airports and Intermodal Connections. OECD.

Heyes, A., (2009). 'Is environmental regulation bad for competition? A survey'. Journal of Regulatory Economics. Vol. 36, pp. 1-28.

Hoel, M. and L. Karp (2001): "Taxes and quotas for a stock pollutant with multiplicative uncertainty", Journal of Public Economics 82, 91-114.

Nannerup, N. (1998): "Strategic environmental policy under incomplete information", Environmental and Resource Economics 11, 61-78. 
Oum, T.H., Waters, W.G.I.I., 1997. Recent developments in cost function research in transportation. In: De Rus, G., Nash, C. (Eds.), Recent Developments in Transport Economics. Ashgate Publishing, Aldershot, Hampshire, pp. 33-73.

Peeters, P. M., J. Middel and A. Hoolhorst, (2005) 'Fuel efficiency of commercial aircraft. An overview of historical and future trends'. NLR-CR-2005-669. Peeters Advies/NLR.

Scheelhaase, J.D., W.G. Grimme, and M. Schaefer, M. (2010). 'The inclusion of aviation into the EU emission trading scheme: impacts on competition between European and non-European network airlines'. Transportation Research Part D. Vol. 15, Issue 1, pp. 14-25.

Scheelhaase, J.D., (2010). 'Local emission charges - A new economic instrument at German airports'. Journal of Air Transport Management. Vol. 16, Issue 2, pp. 94-99.

Schoonbeek, L. and de Vries, F.P., (2009). 'Environmental taxes and industry monopolization'. Journal of Regulatory Economics. Vol. 36, pp. 96-104.

Yates, A. and M. B. Cronshaw (2001): "Pollution permit markets with intertemporal trading and asymmetric information", Journal of Environmental Economics and Management 42, 104-118.

\section{Appendix}

Proof of Lemma 1: The entry deterrence quantity of the incumbent in period 2 is given by $Q_{I, 2}^{E D}=\left(9 Z^{2} \lambda_{E}^{2}+18 Z a \delta+2(a-Z)^{2}-18 F\right) / 18 \alpha Z$. Such a quantity must be positive and lower or equal than the market size $a . Q_{I, 2}^{E D}$ is positive if and only if $F \leq F_{1} . Q_{I, 2}^{E D}$ is lower or equal than the market size $a$ if and only if $F \geq F_{0}$. Thus, entry deterrence is possible if and only if $F_{0} \leq F \leq F_{1}$.

Proof of Lemma 2: For a given $\alpha$, the entrant's profits negatively depend on $Q_{I, 2}$, $\frac{\partial \Pi_{E, 3}^{C}}{\partial Q_{I, 2}}=-\alpha Z<0$. 
We know that $\Pi_{E, 3}^{C}\left(Q_{I, 2}^{E D}\right)=0$ and $Q_{I, 2}^{E D}$ is negative for any $F>F_{1}$, thus, independently of the value of $\alpha$ and $Q_{I, 2}$ we have that, for any $F>F_{1}, \Pi_{E, 3}^{C}<0$ and the entry is blocked. This completes the proof.

Proof of Lemma 3: Entry is blocked if $\Pi_{E, 3}{ }^{C}<0$ for $Q_{I, 2}=(a+Z \alpha) / 2$. It is easy to prove that, for such a $Q_{I, 2}, \quad \Pi_{E, 3}^{C}$ is strictly decreasing in $\alpha$, and $\Pi_{E, 3}^{C}=0$ for $\alpha^{*}=\left(-3 a+\sqrt{-72 F+36 Z^{2} \lambda_{e}^{2}+72 Z a \delta+8(a-Z)^{2}+9 a^{2}}\right) / 6 Z$. Thus, if $\alpha>\alpha^{*}$, $\Pi_{E, 3}{ }^{C}<0$ and entry is blocked. $\alpha^{*}$ exists if and only if $F<F_{\min }=\frac{1}{2} Z^{2} \lambda_{E}^{2}-\frac{2}{9} Z a+\frac{1}{9} Z^{2}+\frac{17}{72} a^{2}+Z a \delta$. It is easy to prove that $F_{1}<F_{\min }$ and, thus, $\alpha^{*}$ exists for any $F<F_{1}$. It is straightforward to prove that $\alpha^{*}\left(F_{1}\right)=0$ and that, for every $F<F_{1}, \alpha^{*}$ is a strictly decreasing and concave function of $F$. This completes the proof.

Proof of Lemma 5: If $F_{0} \leq F \leq F_{1}$, entry deterrence is possible. However, the incumbent will choose such an option if the profits he obtains in periods 2 and 3 $\Pi_{I, 2}^{E D}+\Pi_{I, 3}^{E D}$ are higher than the profits he would obtain if he just accommodate the entry $\Pi_{I, 2}^{M}+\Pi_{I, 3}^{C}$. First, let us analyze the properties of the functions $\Pi_{I, 2}^{M}+\Pi_{I, 3}^{C}$ and $\Pi_{I, 2}^{E D}+\Pi_{I, 3}^{E D}$ given by expressions (7) and (8), respectively. On the one hand, $\Pi_{I, 2}^{M}+\Pi_{I, 3}^{C}$ is a strictly increasing and convex function of $\alpha$ for every $\alpha \geq 0$. Moreover, $\Pi_{I, 2}^{M}+\Pi_{I, 3}^{C}=\frac{1}{2} Z^{2} \lambda_{I}^{2}+\frac{1}{9} Z^{2}-\frac{2}{9} Z a+\frac{13}{36} a^{2}$ for $\alpha=0$. On the other hand, $\Pi_{I, 2}^{E D}+\Pi_{I, 3}^{E D}$ tends to $\frac{1}{4}\left(2 Z^{2} \lambda_{I}^{2}-2 Z a+Z^{2}+a^{2}\right)$ as $\alpha$ tends to zero (and hence $Q_{I, 2}$ tends to $a$ ) or, as $\alpha$ tends to infinite (and hence $Q_{I, 2}$ tends to zero). For $\alpha>0$ the function $\Pi_{I, 2}^{E D}+\Pi_{I, 3}^{E D}$ starts to increase in a concave manner till it reaches a unique global maximum, then the function stars to decrease, initially in a concave manner and afterwards in a convex manner. Second, let us compare the functions $\Pi_{I, 2}^{M}+\Pi_{I, 3}^{C}$ and $\Pi_{I, 2}^{E D}+\Pi_{I, 3}^{E D}$. As $\quad \alpha$ tends to zero, $\Pi_{I, 2}^{M}+\Pi_{I, 3}^{C}>\Pi_{I, 2}^{E D}+\Pi_{I, 3}^{E D}$. For $\alpha=\alpha^{*}$, $\Pi_{I, 2}^{M}+\Pi_{I, 3}^{C}<\Pi_{I, 2}^{E D}+\Pi_{I, 3}^{E D}$. Thus, the functions $\Pi_{I, 2}^{M}+\Pi_{I, 3}^{C}$ and $\Pi_{I, 2}^{E D}+\Pi_{I, 3}^{E D}$ must cross once 
in the interval $\left(0, \alpha^{*}\right)$, that is, we can guarantee that there always exists a unique $\bar{\alpha} \in\left(0, \alpha^{*}\right) \quad$ such that if $\alpha<\bar{\alpha}, \quad \Pi_{I, 2}^{E D}+\Pi_{I, 3}^{E D}<\Pi_{I, 2}^{M}+\Pi_{I, 3}^{C}, \quad$ and $\quad$ if $\quad \alpha>\bar{\alpha}$, $\Pi_{I, 2}^{E D}+\Pi_{I, 3}^{E D}>\Pi_{I, 2}^{M}+\Pi_{I, 3}^{C}$. This completes the proof.

Proof of Lemma 6: The threshold $\alpha^{*}$ is higher than one if $-72 F+36 Z^{2} \lambda_{E}^{2}-16 Z a+8 Z^{2}+17 a^{2}+72 Z a \delta-36 Z^{2}-9 a^{2}-36 a Z>0$, and this latter condition is satisfied if any of the following conditions holds: $a>a^{*}=\frac{13}{4} Z-\frac{9}{2} Z \delta+\frac{3}{4} \sqrt{36 Z^{2} \delta^{2}-52 Z^{2} \delta-8 Z^{2} \lambda_{E}^{2}+25 Z^{2}+16 F}$, or $36 Z^{2} \delta^{2}-52 Z^{2} \delta-8 Z^{2} \lambda_{E}^{2}+25 Z^{2}+16 F<0$.

The threshold $\bar{\alpha}$ is higher than one, if the two following conditions hold: (i) $\alpha^{*}>1$ and (ii) $\Pi_{I, 2}^{E D}+\Pi_{I, 3}^{E D}<\Pi_{I, 2}^{M}+\Pi_{I, 3}^{C} \quad$ for $\quad \alpha=1$, that is, if: (i) $\alpha^{*}>1$ and (ii) $324 F^{2}-324 F Z^{2} \lambda_{E}^{2}+252 F Z^{2}-180 F Z a-72 F a^{2}+81 Z^{4} \lambda_{E}^{4}-126 Z^{4} \lambda_{E}^{2}+4 Z^{4}+90 Z^{3} a \lambda_{E}^{2}$ $+20 Z^{3} a+36 Z^{2} a^{2} \lambda_{E}^{2}-48 Z^{2} a^{2}+20 z a^{3}+4 a^{4}>0$.

This completes the proof. 


\section{ÚLTIMOS DOCUMENTOS DE TRABAJO}

2012-05: "Trade-offs between environmental regulation and market competition: airlines, emission trading systems and entry deterrence", Cristina Barbot, Ofelia Betancor, M. Pilar Socorro y M. Fernanda Viecens.

2012-04: "Labor Income and the Design of Default Portfolios in Mandatory Pension Systems: An Application to Chile", A. Sánchez Martín, S. Jiménez Martín, D. Robalino y F. Todeschini.

2012-03: "Spain 2011 Pension Reform", J. Ignacio Conde-Ruiz y Clara I. Gonzalez.

2012-02: "Study Time and Scholarly Achievement in PISA", Zöe Kuehn y Pedro Landeras.

2012-01: "Reforming an Insider-Outsider Labor Market: The Spanish Experience", Samuel Bentolila, Juan J. Dolado y Juan F. Jimeno.

2011-13: "Infrastructure investment and incentives with supranational funding", Ginés de Rus y M. Pilar Socorro.

2011-12: "The BCA of HSR. Should the Government Invest in High Speed Rail Infrastructure?", Ginés de Rus.

2011-11: "La rentabilidad privada y fiscal de la educación en España y sus regiones", Angel de la Fuente y Juan Francisco Jimeno.

2011-10: "Tradable Immigration Quotas", Jesús Fernández-Huertas Moraga y Hillel Rapoport.

2011-09: "The Effects of Employment Uncertainty and Wealth Shocks on the Labor Supply and Claiming Behavior of Older American Workers", Hugo Benítez-Silva, J. Ignacio García-Pérez y Sergi Jiménez-Martín.

2011-08: "The Effect of Public Sector Employment on Women's Labour Martket Outcomes", Brindusa Anghel, Sara de la Rica y Juan J. Dolado.

2011-07: "The peer group effect and the optimality properties of head and income taxes", Francisco Martínez-Mora.

2011-06: "Public Preferences for Climate Change Policies: Evidence from Spain", Michael Hanemann, Xavier Labandeira y María L. Loureiro.

2011-05: "A Matter of Weight? Hours of Work of Married Men and Women and Their Relative Physical Attractiveness", Sonia Oreffice y Climent Quintana-Domeque.

2011-04: "Multilateral Resistance to Migration", Simone Bertoli y Jesús Fernández-Huertas Moraga.

2011-03: "On the Utility Representation of Asymmetric Single-Peaked Preferences", Francisco Martínez Mora y M. Socorro Puy.

2011-02: "Strategic Behaviour of Exporting and Importing Countries of a Non-Renewable Natural Resource: Taxation and Capturing Rents", Emilio Cerdá y Xiral López-Otero.

2011-01: "Politicians' Luck of the Draw: Evidence from the Spanish Christmas Lottery", Manuel F. Bagues y Berta Esteve-Volart.

2010-31: $\quad$ "The Effect of Family Background on Student Effort", Pedro Landeras.

2010-29: "Random-Walk-Based Segregation Measures", Coralio Ballester y Marc Vorsatz.

2010-28: "Incentives, resources and the organization of the school system", Facundo Albornoz, Samuel Berlinski y Antonio Cabrales.

2010-27: "Retirement incentives, individual heterogeneity and labour transitions of employed and unemployed workers", J. Ignacio García Pérez, Sergi Jimenez-Martín y Alfonso R. SánchezMartín.

2010-26: "Social Security and the job search behavior of workers approaching retirement", J. Ignacio García Pérez y Alfonso R. Sánchez Martín.

2010-25: "A double sample selection model for unmet needs, formal care and informal caregiving hours of dependent people in Spain", Sergi Jiménez-Martín y Cristina Vilaplana Prieto.

2010-24: "Health, disability and pathways into retirement in Spain", Pilar García-Gómez, Sergi JiménezMartín y Judit Vall Castelló.

2010-23: Do we agree? Measuring the cohesiveness of preferences", Jorge Alcalde-Unzu y Marc Vorsatz.

2010-22: "The Weight of the Crisis: Evidence From Newborns in Argentina", Carlos Bozzoli y Climent Quintana-Domeneque.

2010-21: "Exclusive Content and the Next Generation Networks"., Juan José Ganuza and María Fernanda Viecens.

2010-20: "The Determinants of Success in Primary Education in Spain", Brindusa Anghel y Antonio Cabrales.

2010-19: "Explaining the fall of the skill wage premium in Spain", Florentino Felgueroso, Manuel Hidalgo y Sergi Jiménez-Martín.

2010-18: "Some Students are Bigger than Others, Some Students' Peers are Bigger than Other Students' Peers", Toni Mora y Joan Gil.

2010-17: "Electricity generation cost in isolated system: the complementarities of natural gas and renewables in the Canary Islands", Gustavo A. Marrero y Francisco Javier Ramos-Real.

2010-16: "Killing by lung cancer or by diabetes? The trade-off between smoking and obesity", Federico A. Todeschini, José María Labeaga y Sergi Jiménez-Martín.

2010-15: "Does gender matter for academic promotion? Evidence from a randomized natural experiment", Natalia Zinovyeva y Manuel F. Bagues. 